\title{
Produção do maracujazeiro e resistência mecânica do solo com biofertilizante sob irrigação com águas salinas ${ }^{1}$
}

\author{
Production of the yellow passion fruit and the mechanical resistance of the soil with \\ biofertilizer under irrigation with saline water
}

\author{
Thiago Jardelino Dias ${ }^{2 *}$, Lourival Ferreira Cavalcante ${ }^{3}$, Maurício Javier Leon ${ }^{3}$, Gaudêncio Pereira Santos ${ }^{4}$ e \\ Robson Pontes de Freitas Albuquerque ${ }^{4}$
}

\begin{abstract}
Resumo - O trabalho teve como objetivo avaliar os efeitos de águas de irrigação com níveis crescentes de salinidade e frequências de aplicação de biofertilizante bovino sobre a produção do maracujazeiro amarelo e a resistência mecânica do solo à penetração (RSP). $\mathrm{O}$ experimento foi desenvolvido no município de Remígio (PB), com os tratamentos distribuídos em arranjo fatorial $5 \times 4$, correspondente aos valores de condutividade elétrica (CE) da água de irrigação: 0,$5 ; 1,5 ; 2,5 ; 3,5$ e 4,5 dS m$~^{-1}$ e quatro frequências de aplicação do biofertilizante: sem biofertilizante (SB), aplicação uma semana antes do transplantio (1 SAT), a cada 90 dias a partir do transplantio (90 DAT) e, uma semana antes e a cada 90 dias após o transplantio (1 SAT + $90 \mathrm{DAT})$. O aumento da CE das águas comprometeu a capacidade produtiva do maracujazeiro amarelo, em termos de número de frutos colhidos e produção por planta, sendo os maiores declínios registros nas plantas irrigadas com águas de CE igual e superior a 2,5 dS m${ }^{-1}$. As maiores frequência de aplicação do insumo orgânico promoveram incremento da produção por planta. Os valores da RSP até a profundidade de $40 \mathrm{~cm}$, apesar de aumentarem com a profundidade do perfil, foram abaixo de $2000 \mathrm{Kpa}$ o que não compromete o crescimento radicular e a produtividade do maracujazeiro amarelo. As aplicações das águas salinas aumentaram a resistência mecânica com menores valores nos solos com o insumo orgânico aplicado $1 \mathrm{SAT}+90$ DAT e aos 90 DAT.
\end{abstract}

Palavras-chave - Passiflora edulis. Produtividade. Penetrômetro. Salinidade. Efluente orgânico.

\begin{abstract}
The study aimed to evaluate the effects of irrigation water with increasing salinity levels and the application frequency of bio-fertilizer on the production of yellow passion fruit and soil resistance to penetration (RSP). The experiment was conducted in the municipality of Remígio (PB), Brazil, with treatments distributed in a $5 \mathrm{x} 4$ factorial design corresponding to levels of electrical conductivity (EC) of the irrigation water of $0.5 ; 1.5 ; 2.5 ; 3.5$ and $4.5 \mathrm{dS} \mathrm{m}^{-1}$ and to four frequencies of the application of bovine bio-fertilizer: no biofertilizer (WB); with the application of bovine bio-fertilizer one week before transplanting (1 WBT); with an application every 90 days after transplanting (90 DAT); and bovine bio-fertilizer applied one week before and every 90 days after transplanting $(1 \mathrm{WBT}+90 \mathrm{DAT})$. The increase of the EC of the water compromised the productive capacity of the passion fruit in terms of fruit number and yield per plant. The largest losses were recorded in plants irrigated with water with an EC equal to or greater than $2.5 \mathrm{dS} \mathrm{m}^{-1}$. The highest frequency of organic raw material application promoted an increase in production per plant. The values of the RSP to a depth of $40 \mathrm{~cm}$, although increasing with the depth profile, were below $2000 \mathrm{kPa}$ which does not impair root growth or the productivity of passion fruit. The application of saline water increased mechanical resistance, with lower values in soils where organic raw material was used (1 WBT + 90 DAT).
\end{abstract}

Key words - Passiflora edulis. Productivity. Penetrometer. Salinity. Organic effluent.

\footnotetext{
* Autor para correspondência

${ }^{1}$ Recebido para publicação em 31/08/2010; aprovado em 31/01/2011

Trabalho submetido e selecionado no primeiro Simposio Brasileiro de Salinidade realizado de 12-15/10/2010 em Fortaleza, Ceará, Brasil; parte da tese de Doutorado do primeiro autor (PPGA/CCA/UFPB), pesquisa financiada pelo Conselho Nacional de Desenvolvimento Científico e Tecnológico (CNPq) ${ }^{2}$ Programa de Pós-Graduação em Agronomia, Centro de Ciências Agrárias/UFPB, Areia-PB, Brasil, 58.309-000, tjardelino@hotmail.com ${ }^{3}$ Departamento de Solos e Engenharia Rural, CCA/UFPB, Areia-PB, Brasil, lofeca@cca.ufpb.br, mauricio@cca.ufpb.br

${ }^{4}$ Programa de Pós-Graduação em Manejo do Solo e Água, UFPB, Areia-PB, Brasil, gaudenciops@hotmail.com, rpfalbuquerque@yahoo.com.br
} 


\section{Introdução}

O Brasil é o primeiro produtor mundial de maracujáazedo (Passiflora edulis Sims), obtendo no ano de 2005, produção de 614 mil toneladas cultivadas em 45.300 ha (AGRIANUAL, 2009). Nos últimos anos, a produção nacional não supriu a demanda do mercado agroindustrial, o que motivou a expansão da área cultivada do maracujazeiro (PIMENTEL et al., 2009), apesar da produção passar por forte retração, devido a baixa produtividade de 13,55 $\mathrm{t} \mathrm{ha}^{-1}$, resultante da falta de investimento, do baixo emprego de tecnologia de produção e principalmente do cultivo em ambientes com severas restrições hídricas e climáticas, como no Nordeste Brasileiro (FREIRE et al., 2010).

As principais áreas produtoras de maracujá, nos estados da Paraíba e do Rio Grande do Norte, são caracterizadas pela alta evaporação, uso inadequado da drenagem e até mesmo a utilização de água proveniente de mananciais que apresentam condutividade elétrica superior a $1,5 \mathrm{dS} \mathrm{m}^{-1}$, que podem provocar modificações morfológicas, estruturais e metabólicas nas plantas, comprometendo o crescimento, floração, qualidade do fruto, redução do ciclo da cultura e produtividade (GURGEL et al., 2010; NEVES et al., 2010; SILVA et al., 2009).

A irrigação com águas salinas pode comprometer a qualidade edáfica, provocando aumento da densidade, redução da porosidade, da aeração e da disponibilidade de água e de nutrientes às plantas, além de aumentar o impedimentomecânico ao crescimentoradicular, afetandoa formação de novas raízes e prejudicando o estabelecimento da cultura do maracujazeiro (CARVALHO et al., 2006; CUNHA et al., 2002; SOARES et al., 2008). Uma das propriedades físicas importantes para o manejo e estudo da qualidade física dos solos segundo Dexter (2004) e Sá e Santos Junior (2005), é a resistência do solo à penetração (RSP), pois influencia diretamente o crescimento das raízes, comprometendo a produção.

A procura por tecnologias de manejo que possibilitem a exploração de áreas irrigadas com restrições à salinidade e/ou o uso de água salina na agricultura, com viabilidade econômica, minimizando os efeitos ambientais da atividade agrícola, em relação àquelas sob cultivo irrigado convencionalmente, tem sido estudada na cultura do maracujazeiro (CAVALCANTE et al. 2005; MACEDO et al. 2006; RODRIGUES et al., 2008).

A utilização de resíduos orgânicos podem amenizar os efeitos da salinidade da água de irrigação sobre a formação de mudas e na condução e manutenção da capacidade produtiva do maracujazeiro. O biofertilizante é um insumo orgânico que exerce efeito no condicionamento dos solos, atuando como fertilizante, corretivo e inoculante microbiológico (GONDIM et al., 2010), provocando redução na diferença de potencial osmótico entre as plantas e o meio, possibilitando às plantas de maracujazeiro, crescimento, desenvolvimento e produção satisfatória em meios adversamente salinizados (GONDIM et al., 2010; RODRIGUES et al., 2008; SOUZA et al., 2008). No entanto, apesar dos resultados promissores quanto à utilização do biofertilizante na agricultura, são ainda escassos na literatura artigos relacionados à produtividade do maracujazeiro amarelo produzidos em condições de salinidade (CAMPOS et al., 2007; CAVALCANTE; CAVALCANTE, 2006; RODOLFO JÚNIOR et al., 2008).

O objetivo deste trabalho foi avaliar os efeitos de diferentes condutividades elétricas da água de irrigação, associado às épocas de aplicação de biofertilizante, sobre a produção e o número de frutos do maracujazeiro amarelo, bem como o comportamento da resistência mecânica do solo a penetração.

\section{Material e métodos}

O experimento foi instalado no período de setembro de 2008, em pomar de campo aberto na propriedade Macaquinhos, localizado no município de Remígio, PB (6 $53^{\circ} 00^{\prime}$ de latitude Sul, 3602'00" de longitude Oeste e altitude de $470 \mathrm{~m}$ ), de clima do tipo As', quente e úmido, segundo Köppen adaptado ao Brasil (COELHO; SONCIN, 1982).

Os frutos de maracujazeiro amarelo (Passiflora edulis f. flavicarpa Degener) foram colhidos em março de 2009 , sendo que no período de execução do experimento, a temperatura média do ar foi de $25,5{ }^{\circ} \mathrm{C}$, a umidade relativa média foi de $72,6 \%$ e pluviosidade acumulada de $234 \mathrm{~mm}$ (TAB. 1).

Os tratamentos foram distribuídos em blocos casualizados, com três repetições e três plantas por unidade experimental, arranjando fatorialmente em 5 $\mathrm{x} 4$, referente aos valores de condutividade elétrica da água de irrigação (CE): 0,$5 ; 1,5 ; 2,5 ; 3,5$ e 4,5 dS m m $^{-1}$ e quatro épocas de aplicação do biofertilizante liquido bovino: sem a aplicação do biofertilizante (SB); aplicação uma semana antes do transplantio (1 SAT); aplicação a cada 90 dias após o transplantio (90 DAT); e, aplicação uma semana antes e a cada 90 dias após o transplantio (1 SAT + $90 \mathrm{DAT})$.

As plantas de maracujazeiro amarelo foram transplantadas no espaçamento de $3 \times 3 \mathrm{~m}$, conduzidas em recipientes de polietileno, utilizados como lisímetros, com 60 e $50 \mathrm{~cm}$ de altura e diâmetro, respectivamente, 
Tabela 1 - Valores médios mensais de precipitação, umidade relativa do ar e temperatura no período de execução do experimento

\begin{tabular}{cccc}
\hline \multirow{2}{*}{ Meses } & Temperatura $\left({ }^{\circ} \mathrm{C}\right)$ & Umidade relativa $(\%)$ & Precipitação $(\mathrm{mm})$ \\
\cline { 2 - 4 } & 23,2 & 2008 & 37 \\
\hline Setembro & 23,4 & 72,4 & 0 \\
Outubro & 25,4 & 70,6 & 0 \\
Novembro & 25,9 & 70,4 & 7 \\
Dezembro & & 71,1 & 35 \\
\hline Janeiro & 26,5 & 2009 & 126 \\
Fevereiro & 27,4 & 72,6 & 29 \\
Março & 26,9 & 80,3 & 33,4 \\
\hline Média & 25,5 & 71,1 & 72,6 \\
\hline
\end{tabular}

e capacidade para $158 \mathrm{dm}^{3}$ de substrato. O substrato foi preparado a partir de uma mistura dos $10 \mathrm{~cm}$ superficiais de um solo de textura arenosa $(85 \%$ areia, $9,5 \%$ silte e $9,5 \%$ de argila) e esterco bovino curtido $(\mathrm{C} / \mathrm{N}=16 / 1)$, nas proporções de 9:1 (solo:esterco bovino), acondicionando $150 \mathrm{dm}^{3}$ por recipiente.

A irrigação foi realizada diariamente a partir do transplantio das mudas, pelo método localizado por gotejamento, utilizando dois gotejadores tipo Catife, com vazão de $3,75 \mathrm{~L} \mathrm{hora}^{-1}$, cada um, a $20 \mathrm{~cm}$ do caule, com fornecimento de lâmina $20 \%$ superior à evapotranspiração de referência do dia anterior, obtida com base na evaporação de Tanque "A” (GONDIM et al., 2009).

Por fermentação anaeróbica, o biofertilizante bovino foi preparado durante 30 dias (SANTOS; AKIBA, 1996), utilizando partes iguais de esterco bovino fresco de bovino e água não salina $\left(\mathrm{CEa} \leq 0,5 \mathrm{dS} \mathrm{m}^{-1}\right)$. $\mathrm{O}$ volume de biofertilizante aplicado foi constante para todos os tratamentos, sendo que, antes de cada aplicação, o biofertilizante foi diluído em água não salina na proporção de $1: 1$, e avaliado como água para irrigação (TAB. 2), aplicando $10 \%$ do volume do substrato contido no recipiente.
Os frutos foram colhidos quando apresentavam entre 25 e $50 \%$ da coloração da casca amarela, contados e pesados.

Os dados de resistência mecânica do solo à penetração foram obtidos com penetrômetro eletrônico, modelo FALKERPenetroLOG ${ }^{\circledR}$ - PLG 1020, com eficiência eletrônica para aquisição de dados (PEREIRA et al., 2002). Os substratos foram irrigados 12 horas antes da amostragem objetivando manter o solo na capacidade de campo durante a leitura (VAZ, et al., 2002). Procedeu-se à amostragem de 60 pontos da área experimental (lisímetros), referentes a três repetições por tratamento. $\mathrm{O}$ penetrômetro foi configurado para registrar leituras a cada $5 \mathrm{~cm}$ de incremento de profundidade até à profundidade máxima de $40 \mathrm{~cm}$.

As análises estatísticas foram efetuadas utilizando o programa SAS versão 8.0 (SAS Inst., Cary, Estados Unidos), adotando para as variáveis qualitativas conversão em escala numérica (1 - SB, 2 - 1SAT, 3 90 DAT e 4 - 1 SAT + 90 DAT), sendo os resultados submetidos às análises de variância e de regressão (FERREIRA, 2000).

Tabela 2 - Análise química do biofertilizante bovino como água para irrigação

\begin{tabular}{|c|c|c|c|c|c|c|c|c|c|c|}
\hline $\mathrm{pH}$ & $\mathrm{CE}$ & RAS & $\mathrm{Ca}^{2+}$ & $\mathrm{Mg}^{2+}$ & $\mathrm{K}^{+}$ & $\mathrm{Na}^{+}$ & $\mathrm{SO}_{4}^{2-}$ & $\mathrm{CO}_{3}^{2-}$ & $\mathrm{HCO}_{3}^{-}$ & $\mathrm{Cl}^{-}$ \\
\hline & $\mathrm{dS} \mathrm{m} \mathrm{m}^{-1}$ & $\mathrm{mmol} \mathrm{L}^{-1}$ & ------ & ----- & ---- & ---- $n$ & $1_{c} L^{-1}-$ & 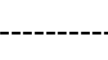 & 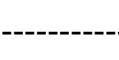 & ---- \\
\hline 6,55 & 2,76 & 3,41 & 4,13 & 7,02 & 7,98 & 8,03 & 5,08 & ALD & 1,12 & 21,81 \\
\hline
\end{tabular}

$\mathrm{CE}=$ Condutividade elétrica a $25^{\circ} \mathrm{C}$; RAS $=$ Razão de adsorção de sódio $\left[\mathrm{Na}^{+} /\left(\mathrm{Ca}^{2+}+\mathrm{Mg}^{2+} / 2\right)^{1 / 2}\right] ;$ ALD $=$ Aquém do limite de detecção 


\section{Resultados e discussão}

A análise estatística verificou diferença significativa para a produção do maracujazeiro amarelo submetido às condutividades elétricas da água de irrigação e as frequências de aplicação do biofertilizante.

Os efeitos dos sais presentes na água de irrigação provocaram redução da produção por planta de maracujazeiro amarelo, com superioridade para os tratamentos com água de $0,5 \mathrm{dS} \mathrm{m}^{-1}$, que apresentaram uma produção de $10,76 \mathrm{~kg}$ planta $^{-1}$ (FIG. 1). As produções de 8,76 e $7,51 \mathrm{~kg}$ planta $^{-1}$, não diferiram estatisticamente entre as águas de condutividade elétrica de 1,5 e $2,5 \mathrm{dS} \mathrm{m}^{-1}$, o que também ocorreu com as de 3,5 e 4,5 $\mathrm{dS} \mathrm{m}^{-1}$, mas com produções mais baixas respectivamente 6,64 e $6,76 \mathrm{~kg}_{\text {planta }}{ }^{-1}$.

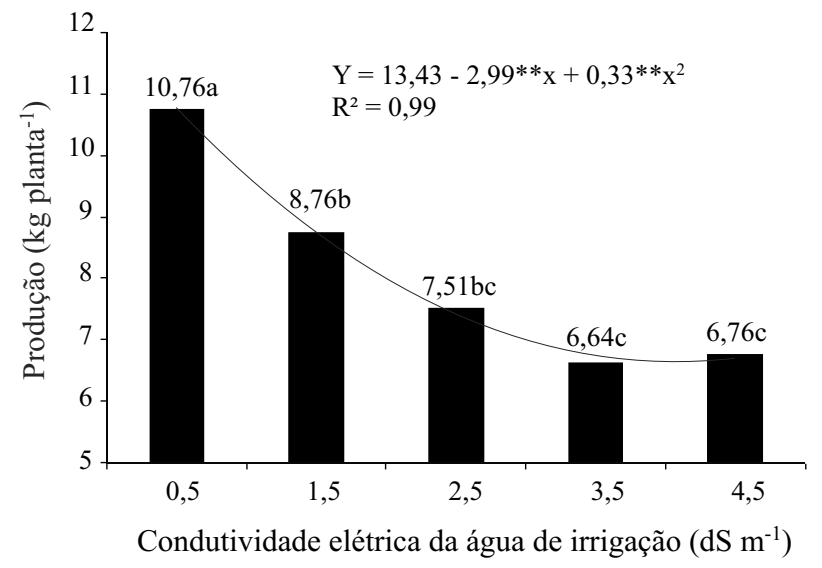

Figura 1 - Produção por planta de maracujazeiro amarelo, em função da salinidade de água de irrigação

A produção por planta apresentou declínio de $62 \mathrm{e}$ $59 \%$ (FIG. 1) nas plantas irrigadas respectivamente com

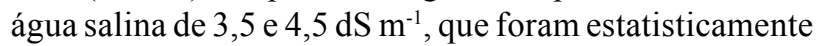
semelhantes com valores médios de $6,7 \mathrm{~kg}$ planta $^{-1}$, em relação à de menor salinidade $\left(0,5 \mathrm{dS} \mathrm{m}^{-1}\right)$.

O modelo quadrático ajustado aos dados de produção indica haver tendência de estabilização da produção a partir da $\mathrm{CEa}$ de $2,5 \mathrm{dS} \mathrm{m} \mathrm{m}^{-1}$, com redução média de 43,27\% em comparação com as plantas irrigadas com água de boa qualidade $\left(0,5 \mathrm{dS} \mathrm{m}^{-1}\right)$. Essa redução está em acordo com a obtida por Cavalcante et al. (2005), ao concluírem que a respectiva cultura tem a produção comprometida quando irrigada com águas de salinidade maior que $2,5 \mathrm{dS} \mathrm{m}^{-1}$. Esse declínio pode ser atribuído também às características físicas do solo como aumento da resistência mecânica à penetração das raízes com o aumento da salinidade da água de irrigação.

Os efeitos das frequências de aplicação do biofertilizante sobre a produção por planta ajustaram ao modelo linear crescente (FIG. 2), com incremento produtivo favorecido pelas maiores frequências de aplicação do insumo orgânico. O tratamento sem o efluente orgânico (SB) resultou em menor produção, seguido com valores intermediários para as aplicações 1 SAT e 90 DAT e com superioridade para o tratamento 1 SAT + 90 DAT. Essa maior produção pode ser atribuída ao adequado fornecimento e disponibilidade de nutrientes fornecidos pelo biofertilizante (CAVALCANTE et al., 2010a; MACEDO et al., 2006), bem como das atividades biológicas do solo, que devem ter contribuído para o aumento da produção por planta de forma proporcional à frequência de aplicação.

As produtividades de $8,86 \mathrm{t} \mathrm{ha}^{-1}$ para plantas irrigadas com CEa de 3,5 e 4,5 $\mathrm{dS} \mathrm{m}^{-1}$ e de 14,35 $\mathrm{tha}^{-1}$ para as irrigadas com água de boa qualidade, superam à média nacional de $12 \mathrm{tha}^{-1} \mathrm{e}$ à nordestina de $11 \mathrm{t} \mathrm{ha}^{-1}$ (AGRIANUAL, 2009). No entanto, foram inferiores à amplitude de 16,8 a 21,4 $\mathrm{t} \mathrm{ha}^{-1}$ apresentada por Macedo et al. (2006) e os 26,11 t ha-1 registrados por Rodrigues et al. (2008), em pomares tratados com biofertilizante supermagro (esterco bovino fresco, água, macronutrientes e micronutrientes), com natural pela mamangava (Xylocopa sp) e artificial pelo homem.

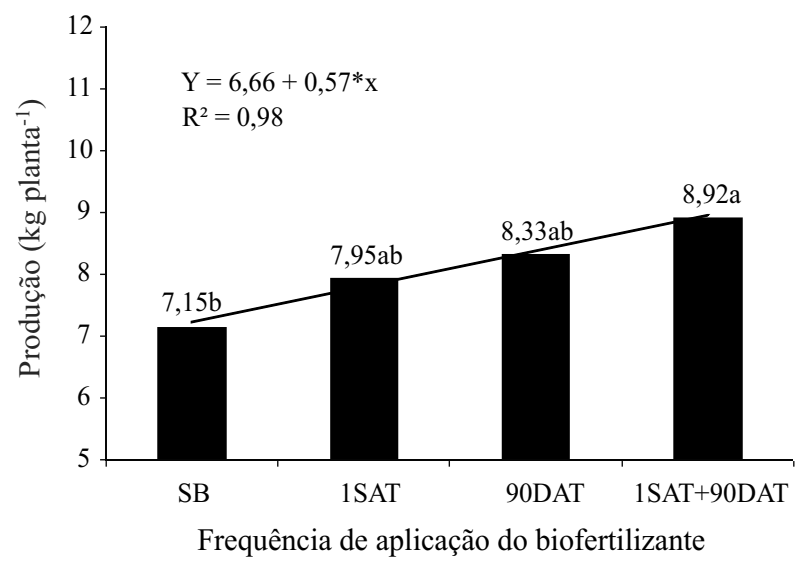

Figura 2 - Produção por planta de maracujazeiro amarelo, em função da frequência de aplicação do biofertilizante: SB - sem biofertilizante; 1 SAT - aplicação do biofertilizante 1 semana antes do transplantio, 90 DAT - a cada 90 dias após transplantio, $1 \mathrm{SAT}+90 \mathrm{DAT}-1$ semana antes e a cada 90 dias, após transplantio 
Para o número de frutos por planta, só foi verificada influência significativa para a CEa de irrigação (FIG. 3), sendo que o biofertilizante não exerceu efeito estatístico sobre esta variável, produzindo em média 55 frutos planta $^{-1}$. O comportamento dos dados foi semelhante ao observado para produção por planta, em função do teor de sais na água de irrigação. Apesar de não haver diferença estatística entre as águas com $\mathrm{CE}$ de 0,5 e $1,5 \mathrm{dS} \mathrm{m}^{-1}$, ocorreu redução de $17 \%$, com valores médios, passando de 70 para 58 frutos planta $^{-1}$. Não foi verificada diferença estatística também entre as águas de condutividade elétrica 3,5 e $4,5 \mathrm{dS} \mathrm{m}^{-1}$,com valores médios de 50 frutos planta ${ }^{-1}$.

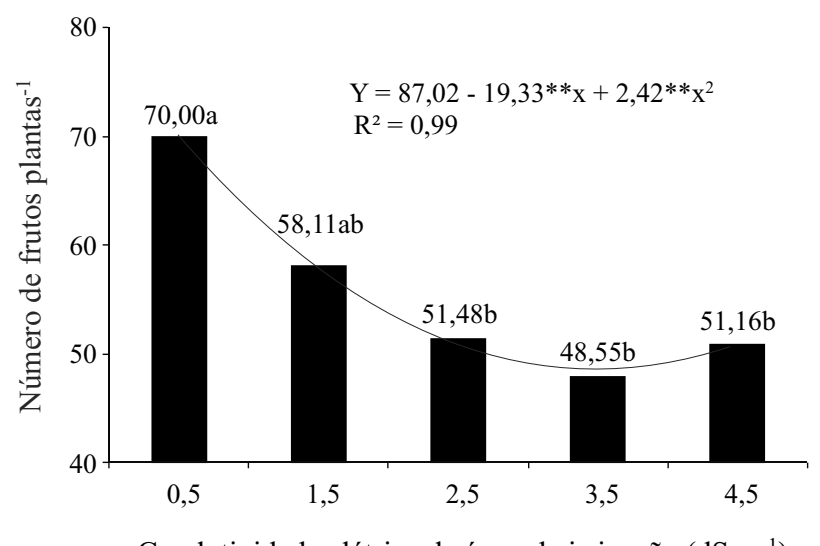

Figura 3 - Número de frutos por planta de maracujazeiro amarelo, em função da salinidade de água de irrigação

Comparativamente aos resultados obtidos por Costa et al. (2001) e Cavalcante et al. (2005) em ambiente com redução de perdas hídricas irrigado com água de condutividade elétrica $3,2 \mathrm{dS} \mathrm{m}^{-1}$ e irrigação com águas de condutividade elétrica 0,$5 ; 1,5$ e $2,5 \mathrm{dS} \mathrm{m}^{-1}$, respectivamente, obtiveram de 18 a 42 frutos planta $^{-1}$ e de 45 a 62 frutos planta $^{-1}$, portanto compatíveis aos resultados evidenciados na presente pesquisa.

O aumento da concentração de sais aplicado via água de irrigação, deve ter reduzido o potencial osmótico da solução do solo, dificultando a absorção de água pelas plantas. Assim, sob estresse salino, as plantas retardam a emissão de folhas e reduzem o crescimento foliar, como estratégia de reduzir as perdas de água por transpiração, diminuindo, consequentemente, a assimilação de carbono e a produção metabólica (FERREIRA NETO et al., 2007; PRISCO; GOMES
FILHO, 2010), refletindo-se em perdas de frutos colhidos e, com efeito, na produção.

Portanto, a acumulação temporal de sais no solo, provavelmente tenha reduzido o número de flores por planta, ou até mesmo, interferido na viabilidade das flores, uma vez que as mesmas não resultaram em frutos formados, em decorrência dos efeitos depressivos da salinidade sobre os processos bioquímicos e fisiológicos das plantas, devido à acumulação de sódio e/ou cloro em concentração elevada (HU; SCHIMIDHALTER, 1997; NETTO et al., 2005; WEST, 1986). Essas reações são típicas de organismos vivos sob condições de estresse abiótico como discutido por Werner e Finkelstein (1995) e Lacerda (2005).

O comportamento do número de frutos, em função das frequências de aplicação do biofertilizante, com média de 55 frutos planta $^{-1}$ foi superior aos valores obtidos por Santos (2004) e Campos (2006), com variação de 31 a 48 frutos planta ${ }^{-1}$ e de 30 a 39 frutos planta $^{-1}$, no cultivo do maracujazeiro com biofertilizante comum e supermagro, respectivamente.

A ausência de influência das frequências de aplicação do biofertilizante sobre o número de frutos por planta de maracujazeiro pode ser atribuída, provavelmente, aos intervalos entre as aplicações de 90 dias, que, em função da época de aplicação e do período de floração, esse insumo possa ter sido incapaz de promover a formação e acumulação de compostos orgânicos nas células, em quantidade suficiente para resultar em maior formação e viabilidade de flores (CAVALCANTE et al., 2007; FREIRE et al., 2010; RODRIGUES et al., 2008).

Os valores da resistência do solo à penetração situaram-se nos níveis toleráveis, isto é, na pressão menor que $2000 \mathrm{Kpa}$ no solo de cada tratamento ao nível de capacidade de campo. Essa condição indica resultados não comprometedores ao crescimento radicular das plantas (SANTI, 2007; SANTI et al., 2009). No entanto, constatou-se aumento médio da resistência mecânica do solo ao longo da profundidade analisada, independente dos tratamentos aplicados (FIG. 4).

$\mathrm{O}$ aumento da resistência do solo à penetração com a profundidade pode ser resposta da dispersão da argila promovida pela irrigação seguida de carregamento e acumulação para as camadas mais profundas, provocando o bloqueio parcial do sistema poroso e redução da qualidade física do solo, com a profundidade (LIMA, 1997; RICHARDS, 1954). Esse fenômeno é mais comum nos solos mais ricos em argila devido contribuírem para a formação de uma camada de impedimento à dinâmica de água, ar, nutrientes 
e crescimento das raízes pelo rearranjamento das partículas, podendo promover a eluviação da fração argila para camadas subsuperficiais (SILVA et al., 2006), estimuladas pelo movimentação constante da água de irrigação.

A interação salinidade da água $\mathrm{x}$ frequência de aplicação do biofertilizante exerceu efeitos sobre a resistência mecânica do solo à penetração. Com base na Figura 5 se constata, tanto no solo sem biofertilizante como para qualquer frequência de sua aplicação, que o aumento da concentração de sais na água de irrigação resultou em maiores valores da resistência à penetração.

A água de boa qualidade $\left(0,5 \mathrm{dS} \mathrm{m}^{-1}\right)$ resultou no menor valor médio de pressão com $128,9 \mathrm{Kpa}$ em relação aos 182,75 Kpa obtidos no solo sob irrigação com água de $1,5 \mathrm{dS} \mathrm{m}^{-1}$, provocando incremento de $41 \%$ na resistência à penetração. Nos tratamentos com águas 2,5 e 3,5 dS m $\mathrm{m}^{-1}$, que apresentaram semelhança estatística entre si, obtiveram média de 223,27 Kpa, aproximadamente $74 \%$ superior a obtida para a água de boa qualidade. No entanto, observa-se que no solo irrigado com água de maior teor salino $\left(4,5 \mathrm{dS} \mathrm{m}^{-1}\right)$ a pressão foi de $347,01 \mathrm{Kpa}$ portanto, $169 \%$ superior ao valor no solo irrigado com água de menor salinidade.

Ao considerar que o solo utilizado para a formação do substrato é de textura arenosa, com apenas 5\% de argila, nessas condições o efeito dispersivo dos sais e de sódio à argilas não se revela expressivo, evidenciando efeitos positivos na melhoria da estrutura pelo aumento do grau de floculação dos sais ao solo (CAVALCANTE et al., 2010b; TANJI, 1990).

Os efeitos das aplicações de biofertilizante nos substratos, estatisticamente apresentaram praticamente as mesmas tendências, não evidenciando redução da resistência a penetração do solo com aumento da frequência de aplicação do biofertilizante. No entanto, observa-se, na Figura 5, que o tratamento sem a aplicação do insumo (SB) sob irrigação com águas de teor salino maior que $2,5 \mathrm{dS} \mathrm{m}^{-1}$, promove incremento de $132 \%$, aumentando de 225,62 para 523,45 Kpa.

Pelos valores da resistência à penetração, observam-se melhorias promovidas pelo biofertilizante em ambientes irrigados com águas de maior salinidade, provavelmente devido à adição da matéria orgânica, associado às populações da macro e microfauna, que desempenham melhorias significativas nas propriedades físicas do solo (CASTRO FILHO et al., 1998), atuando tanto no aumento da agregação como no aumento da aeração do solo.

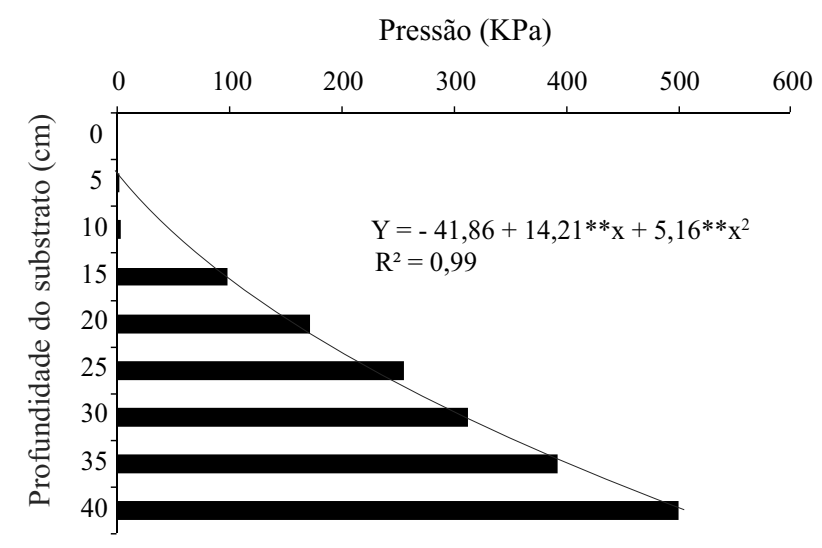

Figura 4 - Valores médios da resistência mecânica do solo à penetração, ao longo profundidade do substrato cultivado com maracujazeiro amarelo

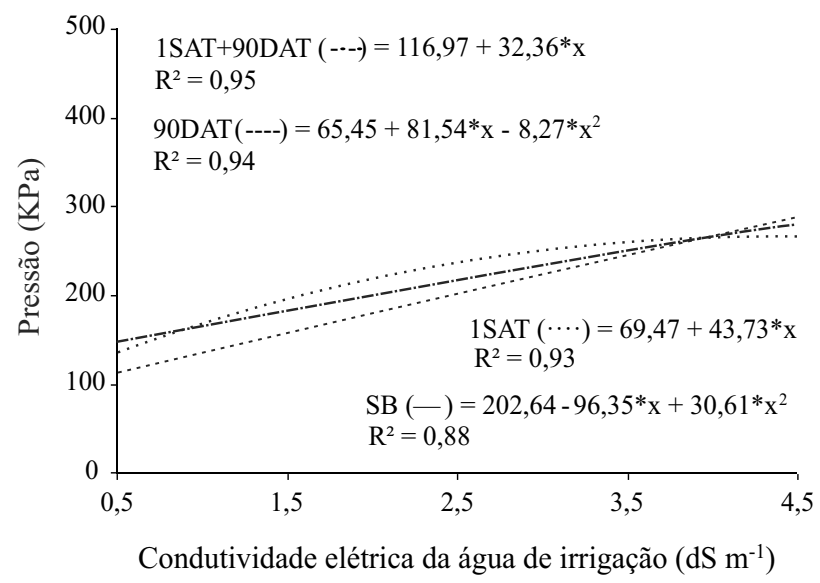

Figura 5 - Resistência mecânica do solo à penetração nos substratos, na profundidade de $0-40 \mathrm{~cm}$, em função da salinidade das águas e frequência de aplicação de biofertilizante. SB - sem biofertilizante (-), 1 SAT - aplicação do biofertilizante 1 semana antes do transplantio (…..), 90 DAT - a cada 90 dias após transplantio (-----), 1 SAT + 90 DAT. - 1 semana antes e a cada 90 dias, após transplantio (-..-)

\section{Conclusões}

1. O aumento da concentração salina da água de irrigação reduziu a produção dos frutos do maracujazeiro amarelo;

2. O biofertilizante bovino interferiu positivamente na produção do maracujazeiro amarelo, com superioridade quando aplicado uma semana antes e a cada 90 dias após o transplantio das mudas (1 SAT + 90 DAT); 
3. A resistência mecânica do solo à penetração, independentemente da salinidade das águas e da frequência de aplicação do biofertilizante, aumentou ao longo da profundidade do perfil;

4. A resistência física do solo diminuiu com o aumento da frequência da aplicação do biofertilizante e aumentou com o teor salino das águas de irrigação.

\section{Agradecimentos}

Os autores agradecem ao Conselho Nacional de Desenvolvimento Científico e Tecnológico e ao Instituto Nacional de Ciência e Tecnologia em Salinidade pelo auxílio financeiro concedido para a realização do trabalho.

\section{Referências}

AGRIANUAL: Anuário da Agricultura Brasileira. 1. ed. São Paulo: FNP, 2009.

CAMPOS, V. B. Comportamento do maracujazeiro amarelo em solo com potássio, biofertilizante e cobertura morta. 2006. 70 f. Monografia (Graduação em Agronomia) - Universidade Federal da Paraíba, Areia.

CAMPOS, V. B. et al. Caracterização física e química de frutos de maracujazeiro amarelo sob adubação potássica, biofertilizante e cobertura morta. Revista Brasileira de Produtos Agroindustriais, v. 9, n. 01, p. 59-71, 2007.

CARVALHO, G. J. et al. Correlação da produtividade do feijão com a resistência à penetração do solo sob plantio direto. Revista Brasileira de Engenharia Agrícola e Ambiental, v. 10, n. 03, p. 765-771, 2006.

CASTRO FILHO, C. et al. L. Estabilidade dos agregados e sua relação com o teor de carbono orgânico num Latossolo Roxo distrófico, em função de sistemas de plantio, rotações de culturas e métodos de preparo das amostras. Revista Brasileira de Ciência do Solo, v. 22, n. 03 p. 527-538, 1998.

CAVAlCANTE, L. F. et al. Água salina e esterco líquido de bovino na formação de mudas de goiabeira Paluma. Revista Brasileira de Fruticultura, v. 32, n. 01, p. 251-261, 2010a.

CAVALCANTE, L. F. et al. Crescimento e produção do maracujazeiro amarelo em solo de baixa fertilidade tratado com biofertilizantes líquidos. Revista Brasileira de Ciências Agrárias, v. 2, n. 01, p. 15-19, 2007.

CAVALCANTE, L. F. et al. Produção do maracujazeiro-amarelo irrigado com água salina em covas protegidas lateralmente contra perdas hídricas. Irriga, v. 10, n. 03, p. 229-240, 2005.

CAVALCANTE, L. F. et al. Recuperação de solos afetados por sais. In: GHEYI, H. R.; DIAS, N. S.; LACERDA, C. F. 1 ed. Manejo da salinidade na agricultura: Estudos básicos e aplicados. Fortaleza: INCT Sal, 2010b. p. 425-448.
CAVAlCANTE, L. F.; CAVALCANTE, I. H. L. Uso de água salina na agricultura. In: CAVALCANTE, L. F.; LIMA, E. M. Algumas frutíferas tropicais e a salinidade. 1. Ed, Jaboticabal: FUNEP, 2006. p. 01-17.

COELHO, M. A.; SONCIN, N. B. Geografia do Brasil. 1. ed. São Paulo: Moderna. 1982. 368p.

COSTA, J. R. M. et al. Caracterização dos frutos de maracujazeiro-amarelo irrigado com água salina. Agriambi, v. 05, n. 01, p. 143-146, 2001.

CUNHA, J. P. A. R. et al. Resistência mecânica do solo à penetração sob diferentes densidades e teores de água. Engenharia na Agricultura, v. 10, n. 01-04, p. 1-7, 2002.

DEXTER, A. R. Soil physical quality: Part I. Theory. Effects of soil texture, density, and organic matter, and effects on root growth. Geoderma, v. 120, n. 03/04, p. 201-214, 2004.

FERREIRA, P. V. Estatística experimental aplicada à agronomia. 2. ed. Maceió: EDUFAL, 2000. 421p.

FERREIRA NETO, M. et al. Qualidade de fruto de coqueiroanão verde em função de nitrogênio e potássio na fertirrigação. Revista Brasileira de Engenharia Agrícola e Ambiental, v. 11, n. 05, p. 453-458, 2007.

FREIRE, J. L. O. et al. Atributos qualitativos do maracujá amarelo produzido com água salina, biofertilizante e cobertura morta no solo. Revista Brasileira de Ciências Agrárias. v. 05, n. 01, p. 102-110, 2010.

GONDIM, S. C. et al. Biofertilizante bovino e salinidade da água na macrofauna do solo cultivado com maracujazeiro amarelo. Revista Verde de Agroecologia e Desenvolvimento Sustentável, v. 05, n. 02, p. 35-45, 2010.

GONDIM, S. C. et al. Produção e composição foliar do maracujazeiro amarelo sob lâminas de irrigação. Caatinga, v. 22 , n. 04 , p. $100-107,2009$.

GURGEL, M. T. et al. Crescimento de meloeiro sob estresse salino e doses de potássio. Revista Brasileira de Engenharia Agrícola e Ambiental, v. 14, n. 01, p. 3-10, 2010.

HU, Y.; SCHMIDHALTER, U. Interactive effects of salinity and macronutrient level on wheat - part II: Composition. Journals Plant Nutrition. v. 20, n. 09, p. 1169-1182, 1997.

LACERDA, C. F. Interação salinidade $\mathrm{x}$ nutrição mineral. In: NOGUEIRA, R. J. C., et al. 1. ed. Estresses ambientais: Danos e benefícios às plantas. Recife: Universidade Federal de Pernambuco, 2005. p. 127-137.

LIMA, L. A. Efeito de sais no solo e na planta. In: GHEYI, H. R.; QUEIROZ, J. E.; MEDEIROS, J. M. 1. ed. Manejo e controle da salinidade da agricultura. Campina Grande: UFPB; SBEA, 1997. p. $113-136$.

MACEDO, J. P. S. et al. Produção de maracujazeiro amarelo em função de biofertilizantes líquidos aplicados ao solo. In: CONGRESSO BRASILEIRO DE FRUTICULTURA, 19, 2006, Cabo Frio. Anais... Cabo Frio: SBF/UENF/UFRRJ, 2006. p. 533. 
NETTO, A. T. et al. Photosynthetic pigments, nitrogen, chlorophyll $a$ fluorescence and SPAD-502 readings in coffee leaves. Scientia Horticulturae, v. 104, p. 199-209, 2005.

NEVES, A. L. et al. Monitoring soil coverage and yield of cowpea furrow irrigated with saline water. Revista Ciência Agronômica, v. 41, n. 01, p. 59-66, 2010.

PEREIRA, J. O. et al. Resistência do solo à penetração em função do sistema de cultivo e teor de água do solo. Revista Brasileira de Engenharia Agrícola e Ambiental, v. 06, n. 01, p. 171-174, 2002.

PIMENTEL, L. D. et al. Custo de produção e rentabilidade do maracujazeiro no mercado agroindustrial da Zona da Mata Mineira. Revista Brasileira de Fruticultura, v. 31, n. 02, p. 397-407, 2009.

PRISCO, J. T; GOMES FILHO, E. Fisiologia e bioquímica do estresse salino em plantas. In: GHEYI, H. R.; DIAS, N. S.; LACERDA, C. F. 1 ed. Manejo da salinidade na agricultura: Estudos básicos e aplicados. Fortaleza: INCT Sal, 2010. cap. ,p. 143-150.

RICHARDS, L. A. Diagnosis and improvement of saline and alkali soils. 1. ed. Washington, D.C: USDA, 1954. 160p. (Handbook, 60).

RODOLFO JÚNIOR, F. et al. Crescimento e produção do maracujazeiro-amarelo em solo com biofertilizantes e adubação mineral com NPK. Caatinga, Mossoró, v. $21 \mathrm{n}$. 05, p. 134-145, 2008.

RODRIGUES, A. C. et al. Caracterização de frutos de maracujazeiro amarelo em solo tratado com biofertilizante supermagro e potássio. Magistra, v. 20, n. 03, p. 264-272, 2008.

SÁ, M. A. C.; SANTOS JUNIOR, J. D. G. Compactação do solo: consequências para o desenvolvimento vegetal. 1 . ed. Planaltina: Embrapa-Cerrados, 26p, 2005.

SANTI, A. L. Relações entre indicadores de qualidade do solo e a produtividade das culturas em áreas com agricultura de precisão. 2007. 150 f. Tese (Doutorado) - Universidade Federal de Santa Maria, Santa Maria.

SANTI, A. L.; AMADO, T. J. C.; FLORA, L. P. D. Eficiência do uso da água e sua influência na variabilidade do potencial produtivo das culturas. In: REUNIÃO DE PESQUISA DE SOJA DA REGIÃO SUL, 37, 2009, Porto Alegre. Resumos... Porto Alegre: Reunião de Pesquisa de Soja da Região Sul, 2009.

SANTOS, A. C.; AKIBA, F. Biofertilizantes líquidos: uso correto na agricultura alternativa. 1. ed. Rio de Janeiro. Seropédica: Imprensa Universitária/UFRRJ. 1996. 35p.

SANTOS, G. D. Avaliação do maracujazeiro-amarelo sob biofertilizantes aplicados ao solo na forma líquida. 2004. 74 f. Dissertação (Mestrado em Manejo de Solo e da Água) Universidade federal da Paraíba, Areia.

SILVA, E. N. et al. Contribuição de solutos orgânicos e inorgânicos no ajustamento osmótico de pinhão-manso submetido à salinidade. Pesquisa Agropecuária Brasileira, v. 44, n. 05, p. 437-445, 2009.

SILVA, G. J.; MAIA, J. C. S.; BIANCHINI, A. Crescimento da parte aérea de plantas cultivadas em vaso, submetidas a irrigação sub-superficial e a diferentes graus de compactação de um Latossolo Vermelho-Escuro distrófico. Revista Brasileira de Ciências do Solo, v. 30, n. 01, p. 31-40, 2006.

SOARES, F. A. L. et al. Crescimento e produção do maracujazeiro amarelo sob irrigação suplementar com águas salinas. Revista Brasileira de Ciências Agrárias, v. 03, n. 02, p. 151-156, 2008

SOUZA, G. B. et al. Salinidade do substrato contendo biofertilizante para a formação de mudas de maracujazeiro irrigado com água salina. Caatinga, v. 21, n. 02, p. 172-180, 2008.

TANJI, K. K. Agricultural salinity assessment and management. New York: ASCE, 1990. 610 p. (Manuals and Reports of Engineering Pratices, 71).

VAZ, C. M. P. et al. Influência da umidade na resistência do solo medida com penetrômetro de impacto. São Carlos: Embrapa Instrumentação Agropecuária. 2002. 5p. (Comunicado Técnico ${ }^{\circ} 51$ ).

WERNER, J. E.; FINKELSTEIN, R. R. Arabidopsis mutants with reduced response to $\mathrm{NaCl}$ and osmotic stress. Physiologia Plantarum, v. 93, n. 04, p. 659-666, 1995.

WEST, D.W. Stress physiology in trees-salinity. Acta Horticulture, v. 175, p. 322-329, 1986. 